\title{
Intravenous Lipid Emulsions Affect Respiratory Outcome in Preterm Newborn: A Case-Control Study
}

\author{
Giovanni Boscarino $^{1}$ (D), Maria Giulia Conti ${ }^{1,2}{ }^{\text {, Francesca De Luca }}{ }^{1}$, Maria Di Chiara ${ }^{1}$, Giorgia Deli ${ }^{1}$, \\ Marco Bianchi ${ }^{1}$, Paola Favata ${ }^{1}$, Viviana Cardilli ${ }^{1}$, Giovanni Di Nardo ${ }^{3}$ (D) Pasquale Parisi ${ }^{3}$ (D) \\ and Gianluca Terrin ${ }^{1, *(\mathbb{D})}$
}

check for

updates

Citation: Boscarino, G.; Conti, M.G.; De Luca, F.; Di Chiara, M.; Deli, G.; Bianchi, M.; Favata, P.; Cardilli, V.; Di Nardo, G.; Parisi, P.; et al.

Intravenous Lipid Emulsions Affect Respiratory Outcome in Preterm Newborn: A Case-Control Study. Nutrients 2021, 13, 1243. https:// doi.org/10.3390/nu13041243

Academic Editor: Giovanna Verlato

Received: 9 March 2021

Accepted: 7 April 2021

Published: 9 April 2021

Publisher's Note: MDPI stays neutral with regard to jurisdictional claims in published maps and institutional affiliations.

Copyright: (c) 2021 by the authors. Licensee MDPI, Basel, Switzerland. This article is an open access article distributed under the terms and conditions of the Creative Commons Attribution (CC BY) license (https:/ / creativecommons.org/licenses/by/ $4.0 /)$.
1 Department of Maternal and Child Health, Policlinico Umberto I Hospital, Sapienza University of Rome, 00161 Rome, Italy; giovanni.boscarino@yahoo.com (G.B.); mariagiulia.conti@uniroma1.it (M.G.C.); francesca27deluca@gmail.com (F.D.L.); maria.dichiara@uniroma1.it (M.D.C.); giorgia.deli7@gmail.com (G.D.); marbi1996@gmail.com (M.B.); favata.paola@alice.it (P.F.); viviana.cardilli@uniroma1.it (V.C.)

2 Department of Molecular Medicine, Sapienza University of Rome, 00185 Rome, Italy

3 Department of Pediatrics, Mental Health \& Sense Organs (NESMOS), Faculty of Medicine \& Psychology, c/o Sant' Andrea Hospital, Sapienza University, 00189 Rome, Italy; giovanni.dinardo@uniroma1.it (G.D.N.); pasquale.parisi@uniroma1.it (P.P.)

* Correspondence: gianluca.terrin@uniroma1.it; Tel.: +39-064-997-2536

\begin{abstract}
Background: Hypertriglyceridemia (HiTG) is a metabolic complication of intravenous lipid emulsions (ILEs) infusion. We aimed to evaluate the influence of HiTG on the respiratory outcome of preterm babies; (2) Methods: We enrolled, in a case-control study, newborns with gestational age $<32$ weeks or birth weight $<1500 \mathrm{~g}$, over a 3-year period. They were divided into cases and controls; cases were defined by the detection of HiTG defined as serum triglycerides (TG) value > $150 \mathrm{mg} / \mathrm{dL}$; (3) Results: We enrolled 40 cases and 105 controls. Cases had an increased incidence of bronchopulmonary dysplasia $(30.0 \%$ vs. $14.3 \%, p<0.05)$ and longer duration of invasive mechanical ventilation (7 days, 95\% CI 4-10 days vs. 4 days, 95\% CI 1-7 days, $p<0.01$ ) compared to controls. Multivariate analysis confirmed that HiTG independently influenced the duration of invasive mechanical ventilation, also in the subgroups with gestational age $\leq 28+6 / 7$ weeks or birth weight $\leq 1000 \mathrm{~g}$; (4) Conclusion: Newborns with HiTG related to ILEs had a longer duration of invasive mechanical ventilation. Temporary suspension or reduction in ILEs in the case of HiTG is associated with an improvement of respiratory outcome.
\end{abstract}

Keywords: hypertriglyceridemia; parenteral nutrition; bronchopulmonary dysplasia (BPD); invasive mechanical ventilation; respiratory distress syndrome; mortality

\section{Introduction}

Malnutrition is one of the major prematurity-related complications. To reduce extrauterine growth retardation (EUGR) as a consequence of malnutrition, current European Society of Pediatric Gastroenterology, Hepatology and Nutrition (ESPGHAN) guidelines recommend high energy intake in parenteral nutrition (PN) soon after birth [1]. This approach is referred to as "aggressive" nutrition. Intravenous lipid emulsions (ILEs), used as part of the total $\mathrm{PN}$, are essential to meet the current nutritional recommendations for preterm newborns [2]. Despite the fact that appropriate energy intake is a primary goal of neonatal nutrition, the safety of high doses of lipids administered by PN is still debated [3-6]. High serum levels of triglycerides (TG) are recognized as a metabolic complication of ILEs infusion, especially in very low birth weight infants (VLBW) [2]. In this population, the risk of hypertriglyceridemia (HiTG) is greater because of limited muscle and fat mass and reduced metabolic capacity due to a decreased hydrolytic capacity of the enzyme lipoprotein lipase [7]. The administration of ILEs has been associated with worse respiratory function in adult patients. This aspect is still controversial in the newborns. 
Early administration of ILEs has been associated with an increased pulmonary vascular resistance [8] and pulmonary arterial lipid deposits have been detected in histological findings of human neonates receiving ILEs [9]. However, less recent evidence did not confirm this association [10]. Thus, the clinical consequences of HiTG on respiratory outcome remain to be defined.

Starting from these considerations, we designed a study to evaluate the relation between HiTG and mechanical ventilation support in preterm newborns.

\section{Materials and Methods}

\subsection{Study Design and Population}

Newborns with gestational age (GA) $<32$ weeks or birth weight $(\mathrm{BW})<1500$ g, receiving PN and consecutively admitted to the neonatal intensive care unit (NICU) of Policlinico Umberto I Hospital, from January 2017 to November 2019 were enrolled in our study. Newborns with congenital diseases, inborn errors of metabolism, congenital infections, familiar history of allergy, use of pre- or probiotics during hospital stay and hospital discharge or death within $72 \mathrm{~h}$ of life were excluded [11-16]. Our population was divided in two study groups, according with plasma TG values: cases (newborns with at least one measurement of serum TG $>150 \mathrm{mg} / \mathrm{dL}$ associated with ILEs) and controls (newborns with serum TG never exceeding $150 \mathrm{mg} / \mathrm{dL}$ ). In our preliminary data, we observed a relation between respiratory condition and levels of TG $>150 \mathrm{mg} / \mathrm{dL}$. Thus, we used in this study the threshold of $150 \mathrm{mg} / \mathrm{dL}$ to define the condition of HiTG. Our primary outcome was the rate of prolonged invasive mechanical ventilation (more the 7 days) while our secondary outcome was the rate of mortality during hospital stay.

\subsection{Data Collection}

Prenatal, perinatal, and postnatal data were retrospectively recorded in a specific data form by researchers not involved in routine clinical practice. In our policy, we collected nutritional data daily on PN, EN and feeding tolerance in a specific database [3,5].

In addition, data regarding neonatal morbidities and administration of invasive or noninvasive mechanical ventilation were collected. We defined morbidity as the presence of at least one of the major prematurity complications including necrotizing enterocolitis (NEC) Bell-Stage $\geq$ II, periventricular leukomalacia (PVL), late-onset culture proven sepsis, retinopathy of prematurity (ROP) and bronchopulmonary dysplasia (BPD). The diagnoses of neonatal morbidities were performed according with standard criteria, by physicians unaware of the study design and aims, as previously described $[17,18]$. We defined "improved respiratory outcome" as the passage from invasive to non-invasive mechanical ventilation or not free oxygen and/or reduction of oxygen requirement. The extrauterine growth restriction (EUGR) was defined in the longitudinal way if the weight loss was more than one SD between birth and discharge [19]. A blinded statistician performed data analysis.

\subsection{Nutritional Protocol}

Nutritional (enteral and parenteral) protocol was previously described [3,20]. In brief, the mother's own milk was administered as soon as possible after birth [20]. Preterm formula was administered when human milk was not available or sufficient. Donor human milk was not available during the entire study period. Minimal enteral feeding (MEF) was started at $10-20 \mathrm{~mL} / \mathrm{kg} /$ day. The amount was increased by $20-30 \mathrm{~mL} / \mathrm{kg} /$ day if enteral nutrition was tolerated [21,22].

The PN, started early after birth, was administered via a central venous access device to maintain adequate fluids, electrolytes and nutrient intakes until full enteral feeding (FEF, $120 \mathrm{kcal} / \mathrm{kg} /$ day) was achieved [3]. As previously described [23], initial lipid (Smoflipid ${ }^{\circledR}$; Fresenius Kabi, Lake Zurich, IL, USA) intake was $1 \mathrm{~g} / \mathrm{kg} /$ day, progressively increased by $0.5-1 \mathrm{~g} / \mathrm{kg}$ up to $3.5 \mathrm{~g} / \mathrm{kg} /$ day at 7 days of life (DOL). We defined total PN (TPN) when PN 
represented more than $70 \%$ of total nutrition (enteral and parenteral) during the first 7 DOL. Plasma TG were measured every $72 \mathrm{~h}$ for all enrolled neonates in PN with ILEs infusion.

\subsection{Statistics}

Statistical analysis was performed using Statistical Package for Social Science software (SPSS Inc., Chicago, IL, USA), version 25.0. We checked for normality using Shapiro-Wilk test. The mean and 95\% confidence interval (CI) summarized continuous variables and number and percentage described categorial variables. We used $\chi^{2}$ test for categorical variable and t-test or Mann-Whitney for paired and unpaired variables.

To evaluate the influence of HiTG on respiratory outcome, independently to GA or BW, we identified a subgroup of newborns with GA $\leq 28+6 / 7$ weeks or BW $\leq 1000 \mathrm{~g}$ (extremely low birth weight, ELBW). We performed a binary regression analysis to evaluate the influences of covariates (FEF reached after 15 DOL, HiTG, administration of prenatal steroids prophylaxis and surfactant and to be small for gestational age, small for gestational age (SGA) at birth) on the duration of prolonged invasive mechanical ventilation (more than 7 days), on BPD and on post-natal steroids administration for the overall population and for the subgroup with GA $\leq 28+6 / 7$ weeks or ELBW. The level of significance for all statistical tests was 2 -sided $(p<0.05)$. In addition, we performed a binary regression analysis to evaluate the influence of covariates (HiTG, gender, to be SGA at birth, Apgar score $\geq 5, \mathrm{pH}$ on cord blood $\geq 7.1$ and morbidity) on secondary outcome.

\section{Results}

Of the 201 eligible newborns, 145 met the selection criteria (Figure 1).

201 newborns with gestational age $<32$ weeks or birth weight $<1500$ grams

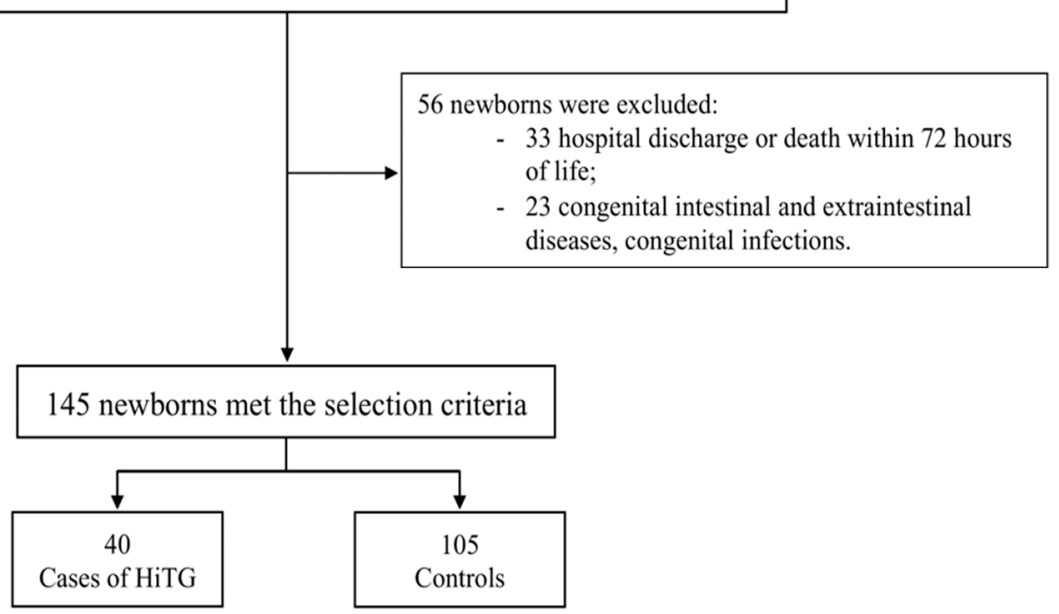

Figure 1. Flow-chart. Notes. HiTG (hypertriglyceridemia).

Data regarding baseline clinical characteristics were reported in Table 1. Newborns in the cases group had lower GA and BW and were more SGA at birth compared to newborns in the controls group (Table 1).

Cases (102 days, 95\% CI 70 to 134 days) had a longer length of hospital stay compared to controls (87 days, 95\% CI 72 to 102 days, $p=0.005$ ). The percentage of newborns fed by enteral nutrition in the first $72 \mathrm{~h}$ of life was lower in cases (50\%) compared to controls (87.6\%, $p<0.001)$; cases achieved FEF later in life (36 days, 95\% CI 23 to 48 days) in comparison with controls ( 21 days, $95 \%$ CI 17 to 25 days, $p<0.001$ ). The percentage of neonates receiving TPN was similar between the two groups (cases $75.0 \%$ vs. controls $66.7 \%, p=0.057)$. The rate of morbidity and mortality were similar between cases and controls ( $40.0 \%$ vs. $28.6 \%, p=0.080 ; 12.5 \%$ vs. $3.8 \%, p=0.052$, respectively). 
Table 1. Baseline clinical characteristics of neonates with hypertriglyceridemia compared with controls.

\begin{tabular}{|c|c|c|c|c|}
\hline & $\begin{array}{l}\text { Cases of HiTG } \\
\quad(n=40)\end{array}$ & $\begin{array}{l}\text { Controls } \\
(n=105)\end{array}$ & $\begin{array}{c}\text { OR } \\
(95 \% \mathrm{CI})\end{array}$ & $p$ Value \\
\hline Maternal age, years & 34 (29 to 38$)$ & 37 (34 to 40$)$ & - & 0.385 \\
\hline$\geq 35$ years, No. $(\%)$ & $20(50.0)$ & $52(49.5)$ & $\begin{array}{c}1.291 \\
(0.587 \text { to } 2841)\end{array}$ & 0.525 \\
\hline Gestational age, weeks & 26 (25 to 28$)$ & 28 (27 to 29$)$ & - & $<0.001$ \\
\hline$\leq 28+6 / 7$ weeks, No. $(\%)$ & $28(70.0)$ & $51(48.6)$ & $\begin{array}{c}0.371 \\
(0.167 \text { to } 0.822)\end{array}$ & 0.013 \\
\hline Birth weight, $g$ & 807 (633 to 981$)$ & 1066 (906 to 1226$)$ & - & $<0.001$ \\
\hline ELBW, No. (\%) & $27(67.5)$ & $33(31.4)$ & $\begin{array}{c}4909 \\
\text { (2217 to } 10.872)\end{array}$ & $<0.001$ \\
\hline SGA, No. $(\%)$ & $12(30.0)$ & $17(16.2)$ & $\begin{array}{c}2.701 \\
(1132 \text { to } 6446)\end{array}$ & 0.022 \\
\hline Male sex, No. (\%) & $16(40.0)$ & $50(47.6)$ & $\begin{array}{c}0.733 \\
(0.350 \text { to } 1536)\end{array}$ & 0.410 \\
\hline Cesarean section, No. (\%) & $29(72.5)$ & $94(89.5)$ & $\begin{array}{c}0.485 \\
(0.172 \text { to } 1365)\end{array}$ & 0.136 \\
\hline $\begin{array}{l}\text { Prenatal steroids } \\
\text { administration }^{\mathrm{a}} \text {, No. }(\%)\end{array}$ & $19(47.5)$ & $71(67.6)$ & $\begin{array}{c}0.535 \\
(0.247 \text { to } 1158)\end{array}$ & 0.110 \\
\hline $\begin{array}{c}\text { Intrauterine growth restriction, } \\
\text { No }(\%)\end{array}$ & $5(12.5)$ & $8(7.6)$ & $\begin{array}{c}1956 \\
(0.596 \text { to } 6417)\end{array}$ & 0.210 \\
\hline Gestational diabetes, No (\%) & $1(2.5)$ & $10(9.5)$ & $\begin{array}{c}0.266 \\
(0.033 \text { to } 2153)\end{array}$ & 0.168 \\
\hline Abruptio placentae, No (\%) & $4(10.0)$ & $10(9.5)$ & $\begin{array}{c}1188 \\
(0.348 \text { to } 4050)\end{array}$ & 0.501 \\
\hline $\begin{array}{c}\text { Pregnancy-induced } \\
\text { hypertension, No. (\%) }\end{array}$ & $11(27.5)$ & $26(24.5)$ & $\begin{array}{c}1337 \\
\text { (0.579 to } 3085)\end{array}$ & 0.495 \\
\hline Thyroid dysfunction, No. (\%) & $6(15.0)$ & $11(10.5)$ & $\begin{array}{c}1.709 \\
(0.583 \text { to } 5014)\end{array}$ & 0.240 \\
\hline Twins, No. (\%) & $10(25.0)$ & $36(34.3)$ & $\begin{array}{c}0.737 \\
(0.320 \text { to } 1696)\end{array}$ & 0.472 \\
\hline 5-min Apgar score & $6(5$ to 7$)$ & $7(6$ to 8$)$ & - & 0.078 \\
\hline$<5$, No. $(\%)$ & 7 (17.5) & $5(4.8)$ & $\begin{array}{c}0.207 \\
(0.061 \text { to } 0.702)\end{array}$ & 0.012 \\
\hline $\mathrm{pH}$ at birth & $7.2(7.1$ to 7.3$)$ & $7.2(7.1$ to 7.3$)$ & - & 0.058 \\
\hline$\leq 7.1$, No. $(\%)$ & $1(2.5)$ & $4(3.8)$ & $\begin{array}{c}1414 \\
(0.153 \text { to } 13.085)\end{array}$ & 0.614 \\
\hline $\begin{array}{c}\text { Birth weight gain before } 14 \\
\text { DOL, No. }(\%)\end{array}$ & $23(57.5)$ & $79(75.2)$ & $\begin{array}{c}0.556 \\
(0.234 \text { to } 1320)\end{array}$ & 0.180 \\
\hline
\end{tabular}

Notes. ${ }^{a}$ Intramuscular steroid cycle in two doses of $12 \mathrm{mg}$ over a 24-h period; HiTG (hypertriglyceridemia); ELBW (extremely low birth weight); SGA (small for gestational age); DOL (days of life). Data were expressed as mean (lower to upper limits $95 \%$ confidence interval), when not specified.

Cases showed a higher rate of newborns with prolonged mechanical ventilation (Table 2). We also observed a longer time of invasive mechanical ventilation, higher incidence of BPD and higher rate of newborns receiving post-natal steroids compared with controls (Table 2).

Newborns with respiratory distress syndrome and HiTG worsened the respiratory outcome, when the infusion of ILEs was not suspended or reduced, more frequently $(57.1 \%)$ compared to newborns that suspended or reduced the infusion of ILEs, $(11.8 \% p=0.038)$ (Figure 2). 
Table 2. Respiratory outcome of neonates with hypertriglyceridemia compared with controls.

\begin{tabular}{|c|c|c|c|c|}
\hline & \multicolumn{2}{|c|}{ Overall } & \multicolumn{2}{|c|}{$\mathrm{GA} \leq 28+6 / 7$ Weeks or ELBW } \\
\hline & $\begin{array}{c}\text { Cases of HiTG } \\
\quad(n=40)\end{array}$ & $\begin{array}{l}\text { Controls } \\
(n=105)\end{array}$ & $\begin{array}{c}\text { Cases of HiTG } \\
\quad(n=34)\end{array}$ & $\begin{array}{l}\text { Controls } \\
(n=57)\end{array}$ \\
\hline Bronchopulmonary Dysplasia & $12(30.0) *$ & $15(14.3)$ & $12(35.3)$ & $13(22.8)$ \\
\hline Caffeine administration & $35(87.5)$ & $97(92.4)$ & $29(85.3)$ & $56(98.2)$ \\
\hline Postnatal steroids administration & $13(32.5)^{* *}$ & $14(13.3)$ & $13(38.2)$ * & $12(21.1)$ \\
\hline Invasive mechanical ventilation & $23(57.5)^{* *}$ & $34(32.4)$ & $22(64.7) *$ & $26(45.6)$ \\
\hline Duration, mean days (95\% CI) & $7(4 \text { to } 10)^{* *}$ & $4(1$ to 7$)$ & $7(4$ to 10$) *$ & $5(1$ to 8$)$ \\
\hline$\geq 7$ days & $10(25.0)^{* *}$ & $6(5.7)$ & $10(29.4)^{* *}$ & $6(10.5)$ \\
\hline Noninvasive mechanical ventilation & $34(85.0)$ & $89(84.8)$ & $29(85.3)$ & $49(86.0)$ \\
\hline Duration, mean days $(95 \% \mathrm{CI})$ & $16(8$ to 23$)$ & $16(10$ to 21$)$ & $16(8$ to 24$)$ & $18(12$ to 25$)$ \\
\hline$\geq 7$ days & $16(40.0)$ & $29(27.6)$ & $16(47.1)$ & $26(45.6)$ \\
\hline
\end{tabular}

Notes. GA (gestational age); ELBW (extremely low birth weight); * vs. controls $p$ value $<0.05$; ${ }^{* *}$ vs. controls $p$ value $<0.01$. Data were expressed as No. (\%), when not specified.

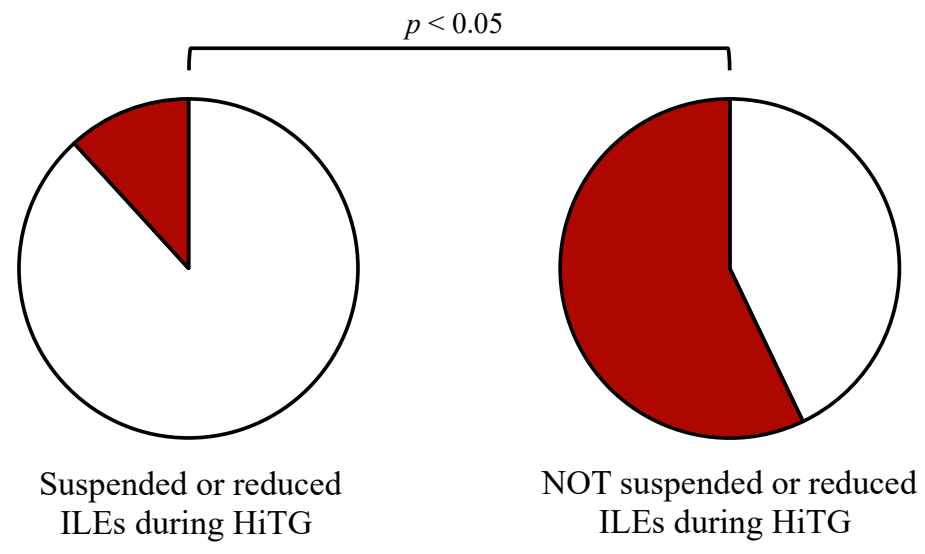

$$
\begin{aligned}
& \text { Respiratory outcome: } \\
& \square \text { Improved or unmodified } \\
& \square \text { Worsened }
\end{aligned}
$$

Figure 2. Respiratory outcome of newborns with respiratory distress syndrome during parenteral nutrition infusion before and after a hypertriglyceridemia episode. Notes. ILEs (intravenous lipid emulsions); HiTG (hypertriglyceridemia).

Newborns with HiTG for whom ILEs were suspended or reduced did not show differences on energy (762.5 kcal/kg/week 95\% CI 578.9 to $946.1 \mathrm{kcal} / \mathrm{kg} /$ week vs. $714.9 \mathrm{kcal} / \mathrm{kg} /$ week $95 \%$ CI 571.2 to $858.7 \mathrm{kcal} / \mathrm{kg} /$ week, $p=0.930$ ) and lipids (24.3 g/ kg/week 95\% CI 18.1 to $30.5 \mathrm{~g} / \mathrm{kg} /$ week vs. $22.7 \mathrm{~g} / \mathrm{kg} /$ week $95 \%$ CI 18.4 to $27.0 \mathrm{~g} / \mathrm{kg} /$ week, $p=1000$ ) intakes given by PN in the first $7 \mathrm{DOL}$, compared to neonates for whom ILEs were not suspended or reduced. Additionally, the rate of EUGR were similar between these groups of newborns $(71.4 \%$ vs. $72.7 \%, p=0.676)$.

Binary logistic regression analysis showed that HiTG is independently related with more than 7 days of invasive mechanical ventilation (Table 3). The multivariate analysis showed that BPD and post-natal steroids administration were not influenced by HiTG (OR 95\% CI 2380, 0.769 to 7369, $p=0.133$ and OR 95\% CI 2643, 0.950 to 7350, $p=0.063$, respectively). 
Table 3. Binary logistic regression analysis evaluating the influences of covariates on prolonged invasive mechanical ventilation (more than 7 days).

\begin{tabular}{ccc}
\hline Covariates & Overall & GA $\leq$ 28 +6/7 Weeks or ELBW \\
\hline FEF $\geq 15$ days (not or yes) & 4106 & 3746 \\
$(0.806$ to 20.931$)$ & 6219 & 5420 \\
Hypertriglyceridemia (not or yes) & $(1655$ to 23.371$)$ ** & $(1395$ to 21.049$) *$ \\
\hline Prenatal steroids administration ${ }^{*}$ (not or yes) & 1821 & 1252 \\
\hline Surfactant administration (not or yes) & $(0.496$ to 6690$)$ & $(0.332$ to 4722$)$ \\
\hline SGA at birth (not or yes) & 2592 & $(0.407$ to 7959$)$ \\
\hline
\end{tabular}

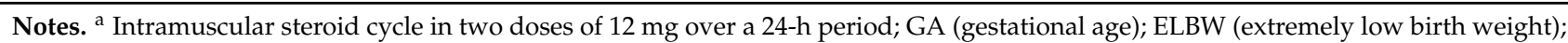
FEF (full enteral feeding); SGA (small for gestational Age); ${ }^{*} p$ value $<0.05$; ${ }^{* *} p$ value $<0.01$. Data were expressed as mean (lower to upper limits $95 \%$ confidence interval).

The baseline clinical characteristics of newborns with GA $\leq 28+6 / 7$ weeks or ELBW were showed in Table S1. Cases, in this subgroup, showed a higher rate and longer duration of invasive mechanical ventilation and more frequent use of post-natal steroids compared to controls (Table 2). In a sensitivity binary regression analysis, including only newborns of the subgroup, we observed that prolonged mechanical ventilation is independently related with HiTG (Table 3). In sensitivity multivariate analysis, BPD and post-natal steroids administration were not dependent on HiTG (OR 95\% CI 2283, 0.650 to 8011, $p=0.193$ and OR 95\% CI 2441, 0.785 to $7587, p=0.123$, respectively). Mortality, for all newborns enrolled including those with GA $\leq 28+6 / 7$ weeks or ELBW, appeared to not be influenced by covariates.

\section{Discussion}

We demonstrated that HiTG in the first 7 DOL is associated with a worse respiratory outcome in preterm newborns. In particular, we observed a higher risk of prolonged invasive mechanical ventilation related with HiTG. These findings are particularly evident in newborns with GA less than 28 weeks or body weight less than $1000 \mathrm{~g}$ at birth. A temporary suspension or reduction in ILEs rapidly improve the respiratory outcome in preterm newborns with HiTG. Finally, the occurrence of HiTG in babies born preterm did not influence the rate of mortality at discharge but prolonged the length of hospital stay.

Previous evidences suggest that higher plasma lipid concentrations could affect lung function in clinical settings different from the neonatal population [24-26]. In particular, an impairment of lung function, oxygenation, compliance of respiratory system, pulmonary vascular resistance and gas exchange following intravenous lipid infusion has been described in critically ill adults [24-26].

Few studies have examined this specific topic with regard to the neonatal population. Periera et al. [27] in a small study including 18 preterm newborns (BW ranging from 770-1890 g), evaluated the effects of ILEs on pulmonary function of premature infants divided in two groups according to postnatal age ( $<1$ week vs. $2-3$ weeks). The authors found that newborns with age $<1$ week developed a significant decrease in pO2 levels after $4 \mathrm{~h}$ from fat infusion. However, clinical outcomes such as the duration of mechanical ventilation or occurrence of BPD were not evaluated in this study. In a small study including 11 newborns with BWs less than $2000 \mathrm{~g}$, AGA, who required respiratory support, Prasertsom et al. [8] observed a worsening of pulmonary vascular resistance associated with ILEs, and a recovery of baseline values after $24 \mathrm{~h}$ from ILEs discontinuation. Additionally, in this paper, no data were reported regarding the effect of ILEs or HiTG on clinical outcome. More recently, in a retrospective study, Giretti et al. [28] identified respiratory distress syndrome as a risk factor for HiTG in preterm newborns with BWs less than $1250 \mathrm{~g}$. 
Despite the authors demonstrating an association between respiratory distress syndrome and lipid tolerance, the occurrence of respiratory distress syndrome preceded HiTG. In a similar population, the same research group, in a retrospective case-control study [29], did not find any relation between HiTG and BPD. Differently from our study, the authors did not correct the results for possible confounding variables. We found a higher occurrence of BDP and post-natal steroids administration in the case of HiTG, however, this relation was not confirmed by the multivariate models. The occurrence of BPD could be related to other factors not considered in the multivariate model and studies with more confounding variables could show a relation. Other well-conducted studies are needed to demonstrate a possible correlation. We considered as the primary outcome the rate of prolonged invasive mechanical ventilation (more the 7 days) and not the occurrence of BPD. We found a relation between HiTG and worsening respiratory outcome in a univariate analysis and we confirmed this relation in a multivariate model. In addition, we performed a sensitivity analysis in a subgroup of newborns with GA $\leq 28+6 / 7$ weeks or ELBW, confirming the results observed in the entire study population.

Similar to previous studies, our findings suggest that GA, BW and to be SGA at birth were significant risk factors for the development of HiTG $[28,30]$. Similar to Sinclair et al. [30], the rate of mortality is not influenced by HiTG. However, Holtrop et al. [31] demonstrated that HiTG could influence the rate of mortality. This could be due to a different TG threshold and different sample size. Our multivariate analysis showed that mortality is not influenced by considered confounding variables (HiTG, gender, to be SGA at birth, Apgar score $\geq 5, \mathrm{pH}$ on cord blood $\geq 7.1$ and morbidity). Although we observed interesting results on the relation between mortality and HiTG, this study was not powered to demonstrate the relation between higher serum TG and the risk of exitus.

The appropriate threshold for serum TG in preterm infants is still a debated topic [30]. The incidence of HiTG and clinical consequences may vary among studies due to different TG thresholds, variable patient demographics and different infusion rates of ILEs [30]. According to the current guidelines for infants on PN, serum plasma TG should not exceed $265 \mathrm{mg} / \mathrm{dL}[2,31,32]$. The differences with our results might be due also to a different threshold of serum TG levels. In our preliminary observation, we found a relation between respiratory conditions and levels of TG $>150 \mathrm{mg} / \mathrm{dL}$. Thus, we considered a threshold value of $150 \mathrm{mg} / \mathrm{dL}$ to define a case of HiTG. We confirmed significant respiratory effect associated with HiTG defined by this threshold. Despite further studies being advocated to determine the threshold value of serum TG as a maker of ILEs toxicity, on the bases of our results, we suggest considering that values more than $150 \mathrm{mg} / \mathrm{dL}$ of TG may have just an impact on respiratory outcome. Thus, we believe that the adjustment of PN prescription could be considered in newborn with respiratory distress and TG levels in the serum $>150 \mathrm{mg} / \mathrm{dL}$. It is important to monitor the metabolic status of infants in PN, in order to suspend or reduce the ILEs in case of HiTG. A well-designed large clinical trial is required to evaluate the effect of regular TG monitoring and titration of ILEs intake on respiratory clinical outcome. A randomized control trial (RCT) assessing the effects of ILEs related HiTG on respiratory clinical outcome in preterm infants is needed to confirm the results of our study. The ILEs infusion's suspension is not recommended by actual guidelines in the case of HiTG ( $>265 \mathrm{mg} / \mathrm{dL}$ ); instead, a temporary reduction in ILEs infusion assuring a minimum linoleic acid intake of $0.25 \mathrm{~g} / \mathrm{kg} /$ day is recommended in preterm infants [2,33]. Despite the fact that reducing ILEs infusion when serum TG levels exceed $150 \mathrm{mg} / \mathrm{dL}$ may potentially compromise nutritional intakes in preterm infants dependent on PN [2], we did not find differences in energy intakes between neonates for whom ILEs were suspended or reduced and neonates for whom they were not. In addition, we also observed a similar occurrence rate of EUGR between these groups of neonates.

It has been reported that ILEs containing fish oil reduce the serum TG levels [34] and improve the respiratory outcome of preterm babies in PN [35]. Both our study groups received the same ILEs containing fish oil. Thus, we are not able to define the role of fish oil on respiratory outcome. 
We hypothesized some mechanisms that may support our results. Preterm newborns in PN with ILEs infusion are at risk of developing lipid micro-emboli, with a decrease in diffusion capacity and oxygenation $[9,25,27]$. We speculate that this alteration in diffusion capacity unbalances the vasomotor tone, causing an alteration of the hemodynamic status of the lungs in this critical population. Increases in vascular tone and subsequent increases in pulmonary artery pressure may have an impact on respiratory distress syndrome. Vasudevan et al. [36] hypothesized that pulmonary artery pressure and eicosanoid metabolites are affected by ILEs in preterm babies. On the other hand, inflammatory cells and type II secretory phospholipase A possibly play a role in deteriorating lung injury [24]. Neutrophils or macrophages activated by lipids in the intracapillary or alveolar space release enzymes and inflammatory mediators, such as type II secretory phospholipase A and platelet activating factor [24]. These probably enhance the alveolar-capillary membrane permeability, tissue inflammation, and surfactant damage [24].

Despite being interesting, the results of our study should be interpreted taking into account several limitations. The association between worse respiratory outcome and HiTG may be related to the effects of chance (random error), bias or confounding factors. We verified that the effects on the lungs of HiTG persisted even after we corrected results for confounding variables for overall and newborn born before to 29 weeks of GA or ELBW at birth. However, confounding variables still unknown or not considered in our statistical analysis may have influenced the results. To limit observer bias, the data for the analysis were collected by researchers not involved in the eligibility assessment and who were unaware of the study outcome and design. We discussed and defined a protocol for the collection, measurement and interpretation of data before starting the study. Besides, a blinded statistician performed the data analysis.

\section{Conclusions}

The HiTG related to ILEs influence the respiratory outcome of babies born preterm, particularly when GA is $\leq 28+6 / 7$ weeks or they are ELBW at birth. Levels of TG should be strictly monitored and the withdrawal or avoidance of ILEs should be considered in newborns with respiratory distress. Our results suggest monitoring the metabolic status of infants in PN, in order to suspend or reduce the ILEs in case of HiTG, thus improving the respiratory outcome of this critically ill population.

Supplementary Materials: The following are available online at https:/ /www.mdpi.com/article/10 $.3390 /$ nu13041243/s1, Table S1. Baseline clinical characteristic of newborns with gestational age $\leq 28$ $+6 / 7$ weeks or birth weight $\leq 1000 \mathrm{~g}$.

Author Contributions: Conceptualization, G.B. and G.T.; methodology, G.B., M.G.C. and G.T.; software, G.B. and G.T.; validation, G.B. and G.T.; formal analysis, G.B., M.G.C. and G.T.; investigation, G.B., M.G.C., F.D.L., M.D.C., G.D., M.B., P.F. and G.T.; data curation, G.B., M.G.C., F.D.L., M.D.C., G.D., M.B., P.F., V.C. and G.T.; writing—original draft preparation, G.B., M.G.C., F.D.L., M.D.C., G.D., M.B., P.F., V.C., G.D.N, P.P. and G.T.; writing-review and editing, G.B., M.G.C., F.D.L., M.D.C., G.D., M.B., P.F., V.C., G.D.N., P.P. and G.T.; visualization, G.B., M.G.C., G.D.N., P.P. and G.T.; supervision, G.T.; project administration, G.T. All authors have read and agreed to the published version of the manuscript.

Funding: This research received no external funding.

Institutional Review Board Statement: The study was conducted according to the guidelines of the Declaration of Helsinki and approved by the Ethics Committee of Policlinico Umberto I Hospital, Sapienza University of Rome (5089, 13 September 2018).

Informed Consent Statement: We anonymized collected data, and an explicit written informed consent was obtained from the parents of each enrolled newborn.

Data Availability Statement: Data are available upon reasonable request. All data relevant to the study are included in the article. Access to raw data would be provided upon request.

Conflicts of Interest: The authors declare no conflict of interest. 


\section{References}

1. Joosten, K.; Embleton, N.; Yan, W.; Senterre, T.; Braegger, C.; Bronsky, J.; Cai, W.; Campoy, C.; Carnielli, V.; Darmaun, D.; et al. ESPGHAN/ESPEN/ESPR/CSPEN Guidelines on Pediatric Parenteral Nutrition: Energy. Clin. Nutr. 2018, 37, $2309-2314$. [CrossRef]

2. Lapillonne, A.; Fidler Mis, N.; Goulet, O.; van den Akker, C.H.P.; Wu, J.; Koletzko, B.; Braegger, C.; Bronsky, J.; Cai, W.; Campoy, C.; et al. ESPGHAN/ESPEN/ESPR/CSPEN Guidelines on Pediatric Parenteral Nutrition: Lipids. Clin. Nutr. 2018, 37, 2324-2336. [CrossRef] [PubMed]

3. Terrin, G.; Coscia, A.; Boscarino, G.; Faccioli, F.; Di Chiara, M.; Greco, C.; Onestà, E.; Oliva, S.; Aloi, M.; Dito, L.; et al. Long-Term Effects on Growth of an Energy-Enhanced Parenteral Nutrition in Preterm Newborn: A Quasi-Experimental Study. PLoS ONE 2020, 15, e0235540. [CrossRef] [PubMed]

4. Stensvold, H.J.; Strommen, K.; Lang, A.M.; Abrahamsen, T.G.; Steen, E.K.; Pripp, A.H.; Ronnestad, A.E. Early Enhanced Parenteral Nutrition, Hyperglycemia, and Death Among Extremely Low-Birth-Weight Infants. JAMA Pediatr. 2015, 169, 1003. [CrossRef] [PubMed]

5. Terrin, G.; Boscarino, G.; Gasparini, C.; Chiara, M.D.; Faccioli, F.; Onestà, E.; Parisi, P.; Spalice, A.; De Nardo, M.C.; Dito, L.; et al. Energy-Enhanced Parenteral Nutrition and Neurodevelopment of Preterm Newborns: A Cohort Study. Nutrition 2021, 111219. [CrossRef]

6. Bonsante, F.; Gouyon, J.-B.; Robillard, P.-Y.; Gouyon, B.; Iacobelli, S. Early Optimal Parenteral Nutrition and Metabolic Acidosis in Very Preterm Infants. PLoS ONE 2017, 12, e0186936. [CrossRef]

7. Koletzko, B.; Goulet, O.; Hunt, J.; Krohn, K.; Shamir, R.; Parenteral Nutrition Guidelines Working Group; European Society for Clinical Nutrition and Metabolism; European Society of Paediatric Gastroenterology, Hepatology and Nutrition (ESPGHAN); European Society of Paediatric Research (ESPR) 1. Guidelines on Paediatric Parenteral Nutrition of the European Society of Paediatric Gastroenterology, Hepatology and Nutrition (ESPGHAN) and the European Society for Clinical Nutrition and Metabolism (ESPEN), Supported by the European Society of Paediatric Research (ESPR). J. Pediatr. Gastroenterol. Nutr. 2005, 41 Suppl 2, S1-S87. [CrossRef]

8. Prasertsom, W.; Phillipos, E.Z.; Van Aerde, J.E.; Robertson, M. Pulmonary Vascular Resistance during Lipid Infusion in Neonates. Arch. Dis. Child. Fetal Neonatal Ed. 1996, 74, F95-F98. [CrossRef]

9. Puntis, J.W.; Rushton, D.I. Pulmonary Intravascular Lipid in Neonatal Necropsy Specimens. Arch. Dis. Child. 1991, 66, 26-28. [CrossRef]

10. Brans, Y.W.; Dutton, E.B.; Andrew, D.S.; Menchaca, E.M.; West, D.L. Fat Emulsion Tolerance in Very Low Birth Weight Neonates: Effect on Diffusion of Oxygen in the Lungs and on Blood PH. Pediatrics 1986, 78, 79-84. [PubMed]

11. Passariello, A. Diarrhea in Neonatal Intensive Care Unit. World J. Gastroenterol. 2010, 16, 2664. [CrossRef] [PubMed]

12. Canani, R.B.; Terrin, G. Recent Progress in Congenital Diarrheal Disorders. Curr. Gastroenterol. Rep. 2011, 13, 257-264. [CrossRef] [PubMed]

13. Ferreira, C.R.; van Karnebeek, C.D.M. Inborn errors of metabolism. In Handbook of Clinical Neurology; Elsevier: Amsterdam, The Netherlands, 2019; Volume 162, pp. 449-481. ISBN 978-0-444-64029-1.

14. Nocerino, R.; Paparo, L.; Terrin, G.; Pezzella, V.; Amoroso, A.; Cosenza, L.; Cecere, G.; De Marco, G.; Micillo, M.; Albano, F.; et al. Cow's Milk and Rice Fermented with Lactobacillus Paracasei CBA L74 Prevent Infectious Diseases in Children: A Randomized Controlled Trial. Clin. Nutr. 2017, 36, 118-125. [CrossRef] [PubMed]

15. Salvia, G.; Cascioli, C.F.; Ciccimarra, F.; Terrin, G.; Cucchiara, S. A Case of Protein-Losing Enteropathy Caused by Intestinal Lymphangiectasia in a Preterm Infant. Pediatrics 2001, 107, 416-417. [CrossRef] [PubMed]

16. Passariello, A.; Terrin, G.; Cecere, G.; Micillo, M.; Marco, G.; Di Costanzo, M.; Cosenza, L.; Leone, L.; Nocerino, R.; Berni Canani, R. Randomised Clinical Trial: Efficacy of a New Synbiotic Formulation Containing Lactobacillus Paracasei B21060 plus Arabinogalactan and Xilooligosaccharides in Children with Acute Diarrhoea. Aliment. Pharmacol. Ther. 2012, 35, 782-788. [CrossRef] [PubMed]

17. Terrin, G.; Di Chiara, M.; Boscarino, G.; Versacci, P.; Di Donato, V.; Giancotti, A.; Pacelli, E.; Faccioli, F.; Onestà, E.; Corso, C.; et al. Echocardiography-Guided Management of Preterms With Patent Ductus Arteriosus Influences the Outcome: A Cohort Study. Front. Pediatr. 2020, 8, 582735. [CrossRef]

18. Terrin, G.; Di Chiara, M.; Boscarino, G.; Metrangolo, V.; Faccioli, F.; Onestà, E.; Giancotti, A.; Di Donato, V.; Cardilli, V.; De Curtis, M. Morbidity Associated with Patent Ductus Arteriosus in Preterm Newborns: A Retrospective Case-Control Study. Ital. J. Pediatr. 2021, 47, 9. [CrossRef]

19. Peila, C.; Spada, E.; Giuliani, F.; Maiocco, G.; Raia, M.; Cresi, F.; Bertino, E.; Coscia, A. Extrauterine Growth Restriction: Definitions and Predictability of Outcomes in a Cohort of Very Low Birth Weight Infants or Preterm Neonates. Nutrients 2020, $12,1224$. [CrossRef]

20. Terrin, G.; Boscarino, G.; Di Chiara, M.; Iacobelli, S.; Faccioli, F.; Greco, C.; Onestà, E.; Sabatini, G.; Pietravalle, A.; Oliva, S.; et al. Nutritional Intake Influences Zinc Levels in Preterm Newborns: An Observational Study. Nutrients 2020, 12, 529. [CrossRef] [PubMed]

21. Terrin, G.; Passariello, A.; Canani, R.B.; Manguso, F.; Paludetto, R.; Cascioli, C. Minimal Enteral Feeding Reduces the Risk of Sepsis in Feed-Intolerant Very Low Birth Weight Newborns. Acta Paediatr. 2009, 98, 31-35. [CrossRef] [PubMed] 
22. Berni Canani, R.; Passariello, A.; Buccigrossi, V.; Terrin, G.; Guarino, A. The Nutritional Modulation of the Evolving Intestine. J. Clin. Gastroenterol. 2008, 42, S197-S200. [CrossRef] [PubMed]

23. Terrin, G.; De Nardo, M.C.; Boscarino, G.; Di Chiara, M.; Cellitti, R.; Ciccarelli, S.; Gasparini, C.; Parisi, P.; Urna, M.; Ronchi, B.; et al. Early Protein Intake Influences Neonatal Brain Measurements in Preterms: An Observational Study. Front. Neurol. $2020,11,885$. [CrossRef] [PubMed]

24. Lekka, M.E.; Liokatis, S.; Nathanail, C.; Galani, V.; Nakos, G. The Impact of Intravenous Fat Emulsion Administration in Acute Lung Injury. Am. J. Respir. Crit. Care Med. 2004, 169, 638-644. [CrossRef] [PubMed]

25. Hageman, J.R.; Hunt, C.E. Fat Emulsions and Lung Function. Clin. Chest Med. 1986, 7, 69-77. [CrossRef]

26. Suchner, U.; Katz, D.P.; Fürst, P.; Beck, K.; Felbinger, T.W.; Senftleben, U.; Thiel, M.; Goetz, A.E.; Peter, K. Effects of Intravenous Fat Emulsions on Lung Function in Patients with Acute Respiratory Distress Syndrome or Sepsis. Crit. Care Med. 2001, 29, 1569-1574. [CrossRef] [PubMed]

27. Periera, G.R.; Fox, W.W.; Stanley, C.A.; Baker, L.; Schwartz, J.G. Decreased Oxygenation and Hyperlipemia during Intravenous Fat Infusions in Premature Infants. Pediatrics 1980, 66, 26-30. [PubMed]

28. Giretti, I.; D’Ascenzo, R.; Correani, A.; Antognoli, L.; Monachesi, C.; Biagetti, C.; Pompilio, A.; Marinelli, L.; Burattini, I.; Cogo, P.; et al. Hypertriglyceridemia and Lipid Tolerance in Preterm Infants with a Birth Weight of Less than $1250 \mathrm{~g}$ on Routine Parenteral Nutrition. Clin. Nutr. Edinb. Scotl. 2021. [CrossRef] [PubMed]

29. Correani, A.; Giretti, I.; Antognoli, L.; Monachesi, C.; Cogo, P.; D'Ascenzo, R.; Biagetti, C.; Carnielli, V.P. Hypertriglyceridemia and Intravenous Lipid Titration During Routine Parenteral Nutrition in Small Preterm Infants. J. Pediatr. Gastroenterol. Nutr. 2019, 69, 619-625. [CrossRef]

30. Sinclair, R.; Schindler, T.; Lui, K.; Bolisetty, S. Hypertriglyceridaemia in Extremely Preterm Infants Receiving Parenteral Lipid Emulsions. BMC Pediatr. 2018, 18, 348. [CrossRef] [PubMed]

31. Holtrop, P.; Swails, T.; Riggs, T. Hypertriglyceridemia in Extremely Low Birth Weight Infants Receiving Lipid Emulsions. J. Neonatal-Perinat. Med. 2015, 8, 133-136. [CrossRef] [PubMed]

32. Toce, S.S.; Keenan, W.J. Lipid Intolerance in Newborns Is Associated with Hepatic Dysfunction but Not Infection. Arch. Pediatr. Adolesc. Med. 1995, 149, 1249-1253. [CrossRef] [PubMed]

33. Vlaardingerbroek, H.; van Goudoever, J.B. Intravenous Lipids in Preterm Infants: Impact on Laboratory and Clinical Outcomes and Long-Term Consequences. In World Review of Nutrition and Dietetics; Calder, P.C., Waitzberg, D.L., Koletzko, B., Eds.; S. KARGER AG: Basel, Switzerland, 2014; Volume 112, pp. 71-80. ISBN 978-3-318-02752-5.

34. Pereira-da-Silva, L.; Nóbrega, S.; Rosa, M.L.; Alves, M.; Pita, A.; Virella, D.; Papoila, A.L.; Serelha, M.; Cordeiro-Ferreira, G.; Koletzko, B. Parenteral Nutrition-Associated Cholestasis and Triglyceridemia in Surgical Term and near-Term Neonates: A Pilot Randomized Controlled Trial of Two Mixed Intravenous Lipid Emulsions. Clin. Nutr. ESPEN 2017, 22, 7-12. [CrossRef] [PubMed]

35. Hsiao, C.-C.; Lin, H.-C.; Chang, Y.-J.; Yang, S.-P.; Tsao, L.-Y.; Lee, C.-H.; Chen, H.-N.; Chen, J.-Y.; Tsai, Y.-G. Intravenous Fish Oil Containing Lipid Emulsion Attenuates Inflammatory Cytokines and the Development of Bronchopulmonary Dysplasia in Very Premature Infants: A Double-Blind, Randomized Controlled Trial. Clin. Nutr. 2019, 38, 1045-1052. [CrossRef] [PubMed]

36. Vasudevan, C.; Johnson, K.; Miall, L.S.; Thompson, D.; Puntis, J. The Effect of Parenteral Lipid Emulsions on Pulmonary Hemodynamics and Eicosanoid Metabolites in Preterm Infants: A Pilot Study. Nutr. Clin. Pract. 2013, 28, 753-757. [CrossRef] [PubMed] 